\title{
APRENDIZAGEM INTERORGANIZACIONAL E MARKETING DE RELACIONAMENTO: UM ESTUDO EXPLORATÓRIO
}

\section{INTERORGANIZATIONAL LEARNING AND RELATIONSHIP MARKETING: AN EXPLORATORY STUDY \\ APRENDIZAJE INTERORGANIZACIONAL Y MARKETING DE RELACIONES: UN ESTUDIO EXPLORATORIO}

Fabiano Larentis

Doutor em Administração (UFRGS)

Professor no Programa de Pós-Graduação em Administração da Universidade de Caxias do Sul (PPGAUCS)

Claudio Baltazar Corrêa de Mello

Doutor em Administração (PUCRS/UCS)

Professor no Programa de Pós-Graduação em Administração da Universidade de Caxias do Sul (PPGAUCS)

Claudia Simone Antonello

Doutora em Administração (UFRGS)

Programa de Pós-Graduação em Administração na Universidade Federal do Rio Grande do Sul (PPGAUFRGS)

Artigo recebido em 21/07/2020. Revisado por pares em 19/10/2020. Reformulado em 20/10/2020. Recomendado para publicação em 18/08/2021, por Ademar Dutra (Editor Científico). Publicado em 31/08/2021. Avaliado pelo Sistema double blind review.

CCopyright 2021 UNISUL-PPGA/Revista Eletrônica de Estratégia \& Negócios. Todos os direitos reservados. Permitida citação parcial, desde que identificada a fonte. Proibida a reprodução total.

Revisão gramatical, ortográfica e ABNT de responsabilidade dos autores. 


\section{RESUMO}

Este trabalho tem como objetivo analisar os processos de aprendizagem advindos dos relacionamentos interorganizacionais nas práticas do marketing de relacionamento entre fornecedores e clientes, através de um estudo qualitativo básico junto a empresas, com entrevistas em profundidade. Identificou-se a preponderância de processos informais de aprendizagem interorganizacional, a partir de experiências, trocas e mudanças de visões de mundo, tendo em vista as situações de aprendizagem, bem como o aprender a confiar, a se comprometer e a cooperar. Os processos formais de aprendizagem, por outro lado, contribuíram para o desenvolvimento de processos informais, e vice-versa.

Palavras-chave: Marketing de Relacionamento; Relacionamentos Interorganizacionais; Aprendizagem Organizacional Situada; Processos Formais e Informais de Aprendizagem; Aprendizagem Interorganizacional.

\section{ABSTRACT}

This paper aims to analyse the learning processes arising from interorganizational relationships, focusing the practices of relationship marketing between suppliers and customers. We conducted a basic qualitative study with companies, through in-depth interviews. As main results we have identified the preponderancy of informal learning process, bearing in mind experiences, sharing and changes of worldviews in learning situations, as well as the learning to trust, to commit and to cooperate. The formal learning processes, on the other hand, has contributed to the development of informal processes, and vice versa.

Keywords: Relationship Marketing; Interorganizational Relationships; Situated Organizational Learning; Formal and Informal Processes of Learning; Interorganizational Learning.

\section{RESUMEN}

Este trabajo tiene como objetivo analizar los procesos de aprendizaje derivados de las relaciones interorganizacionales en las prácticas de marketing relacional entre proveedores y clientes, a través de un estudio cualitativo básico con entrevistas en profundidad. Se identificó la preponderancia de los procesos informales de aprendizaje interorganizacional, en base a experiencias, intercambios y cambios en las visiones del mundo, en vista de las situaciones de aprendizaje, así como aprender a confiar, comprometerse y cooperar. Los procesos formales de aprendizaje, por otro lado, contribuyeron al desarrollo de procesos informales, y viceversa.

Palabras clave: Marketing de Relaciones; Relaciones Interorganizacionales; Aprendizaje Organizacional Situado; Procesos de Aprendizaje Formales e Informales; Aprendizaje Interorganizacional. 


\section{INTRODUÇÃO}

Devido a uma confluência de fatores nos negócios - incluindo a transição para uma economia baseada em serviços, comoditização rápida dos produtos, intensificação da concorrência, crescimento nos mercados emergentes, envelhecimento da população, saturação da propaganda e, acima de tudo, a era digital - fortes relacionamentos com clientes apresentam-se como mais relevantes para a estratégia e o desempenho das empresas (PALMATIER; STEINHOFF, 2019). Nesse ínterim, trata-se o marketing de relacionamento como um processo de interação e engajamento que estabelece, desenvolve e mantém relacionamentos cooperativos de longo prazo benéficos para a empresa e seus públicos (GUMMESSON, 2010, 2017; HÅKANSSON; SNEHOTA, 1995; LARENTIS; ANTONELLO; SLONGO, 2018, 2019; MORGAN; HUNT, 1994).

Por outro lado, a área de marketing, que lida com a compreensão e atendimento das necessidades dos mercados, pode ser considerada uma "área de fronteira" por aproximar organizações diferentes, principalmente fornecedores e clientes. "Fronteira" refere-se aos locais de contato carregado, onde diferenças se encontram e trocas se desenvolvem, considerando conflito, poder e recursos (HALLEY, 1998).

Empresas e clientes que interagem, compartilham recursos, cooperam e desenvolvem projetos, produtos e serviços em conjunto, construindo relacionamentos baseados no comprometimento e na confiança, podem aprender e gerar conhecimentos coletivamente. Em outras palavras, processos de aprendizagem podem se desenvolver a partir dos relacionamentos entre organizações, em um nível interorganizacional, o que se denomina por Aprendizagem Interorganizacional (AI) (KNIGHT, 2002; LARENTIS et al., 2014).

O desenvolvimento, manutenção e desempenho de um relacionamento baseiam-se na aprendizagem dos envolvidos, os quais necessitam aprender como lidar entre si, entender diferentes posições e adquirir conhecimento (ALTINAY; BROOKES, 2012). Al é, portanto, um dos fatores-chave para o desenvolvimento dos Relacionamentos Interorganizacionais - RI (BARROSO-MÉNDEZ; GALERA-CASQUET; VALERO-AMARO, 2015). Paralelamente, a aprendizagem situada coloca pensamento e ação num lugar e tempo específicos, onde situa 
significa envolver indivíduos, atividades e os ambientes para criar significado (ANTONELLO, 2005, 2011).

Este estudo teve como objetivo analisar os processos de aprendizagem advindos dos RIs, tendo as práticas de marketing de relacionamento entre fornecedores e clientes como foco. Considerou-se o processo de aprendizagem nas ações de marketing de relacionamento ocorrendo de forma interorganizacional e situada, entre determinados indivíduos e grupo de diferentes organizações - "pessoal de fronteira".

Com a apresentação ao final dos resultados de um esquema conceitual, este estudo contribui para o avanço do conhecimento em Al, especialmente em seus processos, tendo em vista a análise multinível da Aprendizagem Organizacional (AO). Para Mozzato e Bitencourt (2014), processos de Al, apesar de ainda pouco investigados, têm se tornado um campo relevante de pesquisa, à medida em que pesquisadores buscam compreender os cenários e aspectos envolvidos em relacionamentos organizacionais. Uma vez que a AO se desenvolve através dos níveis individuais e suas interações (grupal, intergrupal, organizacional e interorganizacional) (ANTONELLO; GODOY, 2010), Nogueira e Odelius (2015) indicam como um grande desafio o de viabilizar sua investigação e análise nesse contexto multinível.

\section{REFERENCIAL TEÓRICO}

\subsection{RIS E O MARKETING DE RELACIONAMENTO}

Relacionamentos fundamentados em confiança, comprometimento e cooperação possibilitam desempenho superior e reconhecimento para as organizações presentes em uma cadeia de valor (GUMMESSON, 2010, 2017; MORGAN; HUNT, 1994; SHETH, 2017). Nesse contexto, o marketing de relacionamento, termo utilizado inicialmente em estudos associados ao mercado business-to-business (B-to-B) e de serviços (GUMMESSON, 2010), pode ser definido como um processo de interação e engajamento que desenvolve, viabiliza e mantém relacionamentos cooperativos de longo prazo mutuamente benéficos entre a empresa e seus públicos (principalmente fornecedores e clientes) (GUMMESSON, 2010, 2017; HÅKANSSON; SNEHOTA, 1995; LARENTIS; ANTONELLO; SLONGO, 2018, 2019; MORGAN; HUNT, 1994). Tais elementos revelam a natureza complexa e multifacetada dos relacionamentos, bem como das práticas atreladas ao marketing de relacionamento, à cocriação de valor e ao fazer com os Revista Eletrônica de Estratégia \& Negócios, Florianópolis, v.14, n. 2, mai./ago. 2021. 
outros em rede (GUMMESSON, 2017; PAYNE; FROW, 2017).

Cabe comentar que interação indica que resultados nos negócios são o resultado de ações ou propostas e respostas entre as partes, significa que nenhuma ação é isolada ou independente (GUMMESSON, 2017; HÅKANSSON; SNEHOTA, 1995). Quanto mais as partes estão envolvidas com o relacionamento, menor o risco de sua dissolução e maior a chance de investimentos, incluindo os de cunho não-recuperável (SCHEER; MIAO; PALMATIER, 2015).

Em relação a isso, de acordo com Sheth (2017), práticas de marketing de relacionamento dependem do plano afetivo e emocional dos envolvidos. Estratégias de marketing de relacionamento, por sua vez, não podem ser encaradas como solução para todos os clientes em todas as situações em que uma abordagem de relacionamento seja possível, já que existem clientes que não desejam relacionamentos próximos com seus fornecedores, e vice-versa (GRÖNROOS, 2004; SCHAKETT et al., 2011).

Confiança, comprometimento e cooperação são considerados alguns dos fatoreschave dos relacionamentos (PALMATIER et al., 2006; LARENTIS; ANTONELLO; SLONGO, 2018). A confiança, vista como crença de uma empresa na honestidade e na benevolência da sua contraparte (GEYSKENS; STEENKAMP; KUMAR, 1999), permite maior disposição em partilhar informações, aumenta a segurança em investir no relacionamento, contribui para a criatividade e atenua o comportamento oportunista (PALMATIER et al., 2006; WANG et al., 2008). Com confiança, as partes enxergarão os conflitos como sendo construtivos (MORGAN; HUNT, 1994). No entanto, se reduz em ambientes imprevisíveis e instáveis, (COUGHLAN et al., 2012; KANG; JINDAL, 2015), sendo prejudicada quando pessoas envolvidas no relacionamento são substituídas (NICHOLSON; COMPEAU; SETHI, 2001).

O comprometimento envolve um desejo contínuo de manter um relacionamento (PALMATIER et al., 2006). As partes envolvidas necessitam acreditar na continuidade do relacionamento e no comprometimento entre elas. Por outro lado, baixos níveis de confiança desestimulam o comprometimento (COUGHLAN et al., 2012). Ainda, relacionamentos devem considerar um ambiente social que possibilite o desenvolvimento de uma cooperação efetiva, onde os parceiros percebam as interações passadas de forma positiva e acreditem que ações futuras serão construtivas (MORGAN, 2000). Por sua vez, há influência de confiança tanto em 
comprometimento quanto em cooperação, assim como influência do comprometimento na cooperação: confiança e comprometimento são antecedentes da cooperação (COUGHLAN et al., 2012; MORGAN; HUNT, 1994; PALMATIER et al., 2006).

\subsection{APRENDIZAGEM ORGANIZACIONAL (AO) DE NATUREZA SITUADA}

Percebe-se a aprendizagem como integrante do cotidiano das pessoas, tanto em termos pessoais quanto profissionais, oriunda em grande parte da fonte informal das relações sociais, ou então o ato de evidenciar a experiência contínua: o que as pessoas aprendem são significados intersubjetivos inseridos na cultura (ANTONELLO, 2011; WEICK; WESTLEY, 2004). A aprendizagem nas organizações acontece através da identificação de competências e experiências passadas, podendo basear-se em feedback, discussões, ou mesmo em um ambiente virtual de aprendizagem. A AO chama a atenção dos gestores para os mecanismos que viabilizam o desenvolvimento das capacidades organizacionais; que garantem a habilidade de sentir, interpretar e responder às informações internas e externas da organização; e que em última instância asseguram a vantagem competitiva (BELLE, 2016).

Assim sendo, a maneira como a aprendizagem nas organizações se desenvolve interferirá nas suas capacidades de enfrentar as questões organizacionais relacionadas à transformação, inovação e sustentabilidade (IMRAN; ILYAS; ASLAM, 2016). Embora o indivíduo seja o agente e sujeito do ato de aprender, o conteúdo e o contexto da aprendizagem referem-se ao ambiente coletivo. No contexto organizacional, a gestão do conteúdo de aprendizagem, a acumulação de informações, conhecimento adquirido, sua utilização e transferência interna são os mecanismos que explicam como a aprendizagem acontece (NOGUEIRA; ODELIUS, 2015).

Portanto, a aprendizagem não ocorre somente na mente dos indivíduos, mas também nas suas interações sociais (NICOLINI; GHERARDI, YANOW, 2003). "Toda a atividade na vida dos indivíduos é uma oportunidade para aprendizagem." (ANTONELLO; GODOY, 2010, p. 315). Ou seja, é um fenômeno não somente cognitivo, mas cultural e social, e não somente cognitivo, o que nos remete aos conceitos de prática e de aprendizagem situada (ANTONELLO; GODOY, 2010; GHERARDI, 2005; NICOLINI; GHERARDI; YANOW, 2003). 
Conforme Gherardi (2005), prática é um modo relativamente estável no tempo e socialmente reconhecido, de ordenar itens heterogêneos em um conjunto coerente, situada em contextos específicos de poder e conhecimento: inscrevem posições sociais e relações caracterizadas por expectativas particulares, regras e procedimentos. O conhecimento situase dentro das formas de vida e é afetado por interesses, ideologias e as especificidades das negociações sociais. Como argumentam Brown e Duguid (2001), entender as práticas de trabalho é crítico à compreensão da aquisição de identidade e conhecimento no trabalho.

Assim, a aprendizagem depende das ações, atividades, contextos e cultura na qual se desenvolve ou se situa (LAVE; WENGER, 1991). Ou seja, necessita não somente de sistemas formais, que envolvem treinamento ou uso de banco de dados, mas principalmente da participação no trabalho, de maneira não intencional e não deliberada. Aprendizagem situada, desta forma, coloca pensamento e ação num tempo e espaço específicos. Situar significa envolver indivíduos, o ambiente e as atividades para criar significado (ANTONELLO; 2011; NICOLINI; GHERARDI, YANOW, 2003).

\subsection{APRENDIZAGEM INTERORGANIZACIONAL (AI)}

Al é a aprendizagem no contexto de grupos ou pares de organizações que estão proativamente cooperando, ou seja, em relacionamentos cooperativos (KNIGHT, 2002). Na Al evidenciam-se episódios envolvidos no aprender em como competir e no aprender em como gerar desempenho (GIBB; SUNE; ALBERS, 2017), assim como o interesse das partes no compartilhamento de conhecimento, tanto no tocante ao conteúdo quanto à forma (RAJALA, 2018).

Entende-se a Al como um processo dinâmico que ocorre em relacionamentos cooperativos interorganizacionais, em espaços sociais diferentes, estruturados e não estruturados, incentivando situações de aprendizagem (KNIGHT, 2002; MOZZATO; BITENCOURT, 2014). Em relação a isso, a cooperação envolve atividades de aprendizagem conjunta que funciona como salvaguarda contra o oportunismo (SELNES; SALLIS, 2003), uma vez que a Al depende de comportamentos voltados à interação e à cooperação (ESTIVALETE; PEDROZO, 2018; OLIVEIRA; SILVA, 2020). 
No contexto da $\mathrm{Al}$ as empresas lidam com certos dilemas ao tentarem adquirir conhecimento e tecnologia por meio da utilização da aprendizagem. Em um cenário de aliança de aprendizagem existirá uma tensão significante entre aprender e proteger. Para Yang et al. (2014), ao promover a troca de conhecimento com o seu parceiro de aprendizagem a empresa deverá encarar os perigos da apropriação desse conhecimento, uma vez que ele poderá ser internalizado, limitado e extraído por seu aliado. Desta maneira, pode-se encarar a Al como potencializadora da criação de valor relacional, uma vez que através do acúmulo de experiências e da articulação e codificação de conhecimentos interfere na força dos laços entre parceiros, compensando os efeitos adversos originados da dependência entre as partes (BADIR; O'CONNOR, 2015; KULL; ELLIS, 2016; OLIVEIRA; SILVA, 2020).

No entanto, mesmo que o foco desse conceito seja em organizações, não se pode esquecer que os relacionamentos ocorrem primariamente entre pessoas e grupos de pessoas. Conforme Turley e Geiger (2006), dentro da dimensão interorganizacional a aprendizagem (a) pode ser encarada como algo pessoal (aprender sobre outra pessoa ou depender do indivíduo para ocorrer); (b) se desenvolverá preponderantemente pela ação, pela experiência (não denigre o formal, mas indica suas deficiências); (c) é contextual (relacionada a situações ou contextos específicos); (d) é algo natural (envolve ritmo e esquema de interações sociais); (e) está em aberto (aprender em si nunca é algo completo); e (f) inconsciente ou deliberada? (nem todo conhecimento é explícito, aprende-se no dia a dia, de maneira tácita).

Em relação a isso, em diversos estudos associados a $\mathrm{Rls}$, a $\mathrm{Al}$, semelhante à $\mathrm{AO}$, foi abordada a partir de quatro fases: (a) geração/aquisição (de informações, experiências e trocas); (b) compartilhamento/disseminação; (c) interpretação/produção de sentido; e (d) armazenamento/memória do relacionamento (FANG et al., 2011; GUTIÉRREZ, 2011; O'CASS; WEERAWARDENA, 2010; SÁNCHEZ; SANTOS-VIJANDE; SELNES; SALLIS, 2003). Destaca-se que essas fases envolvem tanto aspectos formais, como processos de treinamento, quanto aspectos informais, como processos de interação e socialização entre indivíduos.

Nesse ínterim, à medida que as partes começam a compartilhar informação, isso se desenvolve em um processo de diálogo. Diálogo constitui um elemento específico que levará à interpretação ou produção de sentido (SELNES; SALLIS, 2003). O diálogo funciona como um processo interativo de aprender em conjunto, frequentemente espontâneo e sem regras, Revista Eletrônica de Estratégia \& Negócios, Florianópolis, v.14, n. 2, mai./ago. 2021. 
limitado por uma intenção de alcançar entendimento mútuo (BALLANTYNE, 2004). Esse compartilhamento e a transferência de conhecimento são facilitados quando interpretados de maneiras semelhantes entre organizações diferentes (TURLEY; GEIGER, 2006).

Relativo a isso, o estudo de Fang et al. (2011) identificou que tanto o compartilhamento de informações quanto a produção de sentido (interpretação) conjunta não tiveram efeito direto na inovação das organizações, mas indireto via memória específica do relacionamento. Ou seja, há dependência da extensão que o conhecimento é mantido pela empresa no decorrer do tempo. Empresas em relacionamentos estáveis podem conceber a interpretação conjunta de informações e experiência geradas da solução de problemas como benéfica para colaboração futura, com forte inclinação para armazenar. No âmbito da Al, deve haver disposição das partes em compartilhar tanto conhecimento explícito quanto tácito (CHILD, 2001).

Além disso, conforme pesquisa de Janowicz-Panjaitana e Noorderhavenb (2008), o excesso de formalização pode obstruir o aprendizado. Similarmente, enquanto comportamentos formais encorajam aprendizagem informal dos interfaceadores, o excesso de formalização a desencoraja. Assim, o uso excessivo de mecanismos estruturais para estimular a aprendizagem pode reduzi-la e fazer com que os interfaceadores se motivem menos a se engajar em comportamentos de aprendizagem informal.

Al possibilita combinação de recursos, por ir além dos interesses específicos das empresas, refinando a especialização de conhecimento e permitindo efeitos sinérgicos (BOUNCKEN; PESCH; KRAUS, 2015). Desta forma, nos processos de Al participam elementos de diferentes sistemas, sendo caracterizados por diferentes identidades e contextos. Al tem que lidar com muita complexidade e dinâmicas devido às diferenças e fragilidades, o que pode levar a barreiras adicionais à aprendizagem (individuais e coletivas). Há também as diferenças culturais, que levam a diferentes percepções da realidade (resultado de um processo contínuo de interpretação e interação entre indivíduos em um sistema social - realidade socialmente construída) (HUELSMANN; LOHMANN; WYCISK, 2006).

Em relação a isso, Larentis et al. (2014) identificaram que a Al constitui-se de bases, processos, resultados e contextos. As bases referem-se à confiança, comprometimento, 
estabilidade e dinâmica relacionais e a aspectos culturais. Os processos associam-se à interação entre aprendizagem formal e informal, entre conhecimento tático e explícito e entre exploration e exploitation, absorção da incerteza, combinação de recursos e aos papéis dos interfaceadores. Os resultados envolvem a aprendizagem de sistemas e conceitos, a aprendizagem de elementos culturais e a cooperação. O contexto, situado, divide-se nos eixos temporal (passado, presente e expectativas futuras dos relacionamentos) e espacial (níveis intra e interorganizacional).

\subsection{APRENDIZAGEM INTERORGANIZACIONAL SITUADA E MARKETING DE RELACIONAMENTO}

Conforme Selnes e Sallis (2003), através do relacionamento, as partes envolvidas identificam maneiras de reduzir custos redundantes, melhorar qualidade e flexibilidade. Do ponto de vista dos fornecedores, melhor conhecimento dos clientes permite o fornecimento de produtos melhores. Com melhor conhecimento dos fornecedores, clientes melhoram a escolha de produto e a satisfação de suas necessidades. A aprendizagem conjunta fortalece o desempenho do relacionamento (ALTINAY; BROOKES, 2012; CHANG; GOTCHER, 2010; LAl et al., 2009). Daí afirmar que as práticas do Marketing de Relacionamento se beneficiam e dependem dos processos de aprendizagem interorganizacional.

A busca de conhecimento sobre os clientes e mercados irá gerar preocupação com a aprendizagem. Isso melhora o grau de resposta do fornecedor para as mudanças de necessidade do intermediário e um equilíbrio adequado entre o uso do conhecimento acumulado e a exploração de novas oportunidades. Por haver efeito menor da turbulência externa nas relações, a percepção de segurança é maior (SÁNCHEZ; SANTOS-VIJANDE; GUTIÉRREZ, 2011). Nesse ínterim, um número considerável de estudos em marketing de relacionamento (LARENTIS; ANTONELLO; SLONGO, 2018; MORGAN; HUNT, 1994; MORGAN, 2000; PALMATIER et al., 2006) focam nas dimensões de confiança, comprometimento e cooperação. Já estudos acerca de Al, aprendizagem em alianças estratégicas e aprendizagem em redes (CHILD, 2001; KNIGHT, 2002; HOLMQVIST, 2003; LANE, 2001) reforçam a aprendizagem colaborativa ou o aprender a cooperar possibilitando benefícios mútuos.

Nesse âmbito, conforme Lane (2001), confiança mútua é condição básica para o desenvolvimento e ampliação da Al, com o importante papel dos interfaceadores, o pessoal 
das fronteiras organizacionais, na Al. Quanto a isso, destaca-se que a aprendizagem permite ampliar as tensões naturais que ocupam o papel do interfaceador (TURLEY; GEIGER, 2006). Ademais, a cooperação leva à estruturação de capacidades organizacionais através das interações sociais e relações políticas, da transferência ou combinação de recursos e da capacidade em aprender (HARDY; PHILLIPS; LAWRENCE, 2003). Entretanto, como a cooperação é resultante de confiança e comprometimento (PALMATIER et al., 2006), para se aprender a cooperar, é necessário aprender a confiar e a se comprometer.

A partir disso, destaca-se a aprendizagem no relacionamento oriunda das práticas do marketing de relacionamento, que reflete uma comunidade de aprendizagem na qual o que é aprendido está profundamente conectado com o relacionamento. Aprendizagem no relacionamento envolve histórias comuns, esquemas de referência e valores das duas partes, que podem ser diferentes dentro das organizações envolvidas (SELNES; SALLIS, 2003).

Selnes e Sallis (2003) identificaram que o comprometimento, a incerteza do ambiente e os ativos específicos do relacionamento interferem na aprendizagem do relacionamento, que por sua vez interfere no desempenho do relacionamento. A aprendizagem no relacionamento também é afetada pela confiança relacional, de ordem afetiva. Em relação ao comprometimento, o desejo de colaborar cria um clima para atividades de aprendizagem no relacionamento. No que tange à incerteza, empresas motivam-se a engajar-se em atividades de aprendizagem conjunta para ganhar algum controle ou para absorver o impacto da incerteza. Relativo aos ativos específicos, muitos dos investimentos neles têm valor limitado fora dele, o que por sua vez aumenta a interdependência entre as partes. Por fim, a confiança facilita aprendizagem, porque cria uma crença entre as partes que o compartilhamento de informações aumenta o "tamanho da torta". Com colaboração e adaptação, as duas partes gradualmente desenvolvem confiança e dependência, o que amplia o comprometimento.

Outro ponto importante é que confiança, um dos aspectos-chave dos relacionamentos, por sua natureza, dificilmente se aprende de forma explícita. Além disso, altos níveis de confiança reduzem dependência de mecanismos formais de controle, o que reduz os custos de transação. Como a confiança tem um forte componente emocional e afetivo, é mais provável que as partes compartilhem informações quando em outra situação. Assim, podem-se construir diálogos construtivos e criativos associados à produção de sentido. Revista Eletrônica de Estratégia \& Negócios, Florianópolis, v.14, n. 2, mai./ago. 2021. 
Partes com confiança mútua provavelmente desenvolvam mais uma memória compartilhada (SELNES; SALLIS, 2003). Em suma, a confiança é um facilitador da aprendizagem (LIU, 2012; SANZO et al., 2012).

No entanto, altos níveis de confiança apresentam um lado negativo, pois passa a existir o risco de uma informação crítica ou negativa não ser compartilhada por interferir na boa atmosfera do relacionamento e o benefício do conflito construtivo pode ser perdido. Altos níveis de confiança podem também produzir falta de busca de informação crítica, assim como pode ocorrer o comportamento oportunista. A convergência entre as partes, com mais valores comuns, pode reduzir os processos de criatividade, mais presentes em grupos heterogêneos. Pode também reduzir a capacidade de questionar pressupostos nos quais as ações são baseadas (SELNES; SALLIS, 2003). Altos níveis de confiança servem como barreira para o desenvolvimento de conhecimento relacional (YANG; LAI, 2012)

O estudo de Selnes e Sallis (2003) indica que a aprendizagem se beneficia mais com níveis moderados de confiança (modelo $U$ invertido). De maneira semelhante, os efeitos positivos da Al no conhecimento armazenado alcança o ponto mais alto com o nível intermediário de confiança, conforme estudo de Yang e Lai (2012). Selnes e Sallis (2003) já haviam sugerido que, em condições de alta confiança, há a necessidade de buscar maior heterogeneidade nos grupos, rotatividade de cargos e a busca de informações produzidas externamente. Por outro lado, quando confiança e controle de informações são combinados, podem complementar-se e contribuir para um melhor desempenho (GUNDLACH; CANNON, 2010). Confiança torna-se viável quando é avaliada em aprendizagem (BALLANTYNE, 2004).

Por fim, considerando os principais elementos constituintes dos relacionamentos, tais como confiança, comprometimento e cooperação (MORGAN; HUNT, 1994; MORGAN, 2000; PALMATIER et al., 2006), pode-se afirmar que eles são dependentes para se desenvolver muito mais das interações sociais provindas dos relacionamentos interpessoais do que de processos formais de aprendizagem. Rls constituem-se de relacionamentos interpessoais (SCHAKETT et al., 2011), com indivíduos interagindo em práticas que perpassam as fronteiras organizacionais. Afinal, práticas conectam coisas, pessoas e eventos, e não respeitam fronteiras (NICOLINI; GHERARDI; YANOW, 2003). 


\section{PROCEDIMENTOS METODOLÓGICOS}

Tendo em vista o objetivo proposto, realizou-se uma pesquisa qualitativa, de caráter exploratório. Como estratégia de pesquisa foi utilizado o estudo qualitativo básico ou genérico, pois buscou-se descobrir e entender um fenômeno, um processo ou as perspectivas e visões de mundo das pessoas envolvidas (MERRIAN; TISDELL, 2016).

Para desenvolver o estudo foram entrevistados sete sujeitos, escolhidos por estarem envolvidos com práticas de marketing de relacionamento das empresas nas quais atuam: um executivo de gestão de canais de uma empresa de serviços financeiros, um executivo da área comercial de uma prestadora de serviços de saúde, um executivo de uma distribuidora de alimentos, um consultor da área de marketing, um executivo da área comercial de uma fornecedora de componentes para móveis, uma executiva da área de negócios de uma empresa fornecedora de componentes para o lar e um representante comercial.

A coleta de dados ocorreu com o uso de entrevistas em profundidade, utilizando-se de um roteiro semiestruturado, construído a partir da literatura de marketing de relacionamento e de aprendizagem interorganizacional, com enfoque nas interações formais e informais de aprendizagem, bem como nos aspectos associados à confiança, comprometimento e cooperação. As entrevistas, cujo número baseou-se no critério da redundância, com duração média de uma hora e meia, foram gravadas e transcritas (MERRIAN; TISDELL, 2016).

Utilizou-se a análise de conteúdo para o tratamento e interpretação dos dados. Foram consideradas, a priori, as macrocategorias (a) relacionamento interorganizacional (categorias formas de interação; maiores desafios e dificuldades presentes); (b) aprendizagem organizacional (categorias processo formais e informais de aprendizagem; dificuldades relacionadas); e (c) aprendizagem interorganizacional (categorias processos formais e informais; aspectos ligados à confiança, comprometimento e cooperação; dificuldades relacionadas). A partir delas, foram identificadas categorias a posteriori, reveladas no esquema conceitual elaborado, apresentado ao final dos resultados.

\section{APRESENTAÇÃO E ANÁLISE DOS RESULTADOS}

\subsection{RIs}

Revista Eletrônica de Estratégia \& Negócios, Florianópolis, v.14, n. 2, mai./ago. 2021. 
No contexto das práticas do marketing de relacionamento, a partir dos relatos dos entrevistados foi possível identificar como aspectos conceituais e positivos o relacionamento profissional com amizade; o relacionamento como solução de problemas; a empatia como aspecto central; as vendas como rotina para ganhar confiança; as ações que criam oportunidade de pensar diferente, apesar dos conflitos; ser transparente e estar preparado para lidar com problemas; as mudanças no relacionamento pela maturidade ou substituição de pessoas; saída de pessoas da empresa, mas permanência do relacionamento; baixa rotatividade como indicador de credibilidade; melhor relacionamento conforme o tratamento dispensado aos seus funcionários; melhoria no relacionamento após existência de conflitos. Como desafios ficaram evidenciados: a empresa sem política ou atitude de relacionamento claro; a insegurança em confiar; as resistências de uma área organizacional em relação à outra; o oportunismo; o cliente pautado pelo preço; os níveis elevados de rotatividade de pessoal; relações de poder. Podemos identificar nesses resultados tanto características da interação quanto rotinas de interação.

Os RIs, primeiramente, implicam em amizade entre pessoas de organizações diferentes, mas com profissionalismo. Devem ser vistos como algo concreto, como resolução de problemas, não somente com entrega de presentes ou de "tapas nas costas". A empatia é tratada com um elemento central para fortalecimento do relacionamento, mas depende de disposição e preparação dos envolvidos. De maneira específica, as vendas em relacionamentos de qualidade (que prezam pela confiança, colaboração, solução de problemas e resultados) devem ser encaradas como rotina que envolve fortalecer a confiança e criar oportunidade de pensar diferente, mesmo com os conflitos. Há também a importância de ser transparente, com o foco em fatos, e de estar preparado para lidar com problemas. Relacionamento não significa ausência de problemas, mas uma maneira diferente de resolvêlos.

Os entrevistados relataram que ocorreram mudanças positivas nos RIs com o aumento da maturidade dos envolvidos, que aprenderam a se relacionar melhor. Esse fato também ocorreu com a entrada de pessoas predispostas a se relacionar mais, tanto interna quanto externamente, mas também com a substituição de pessoas que não foram capazes de desenvolver atividades conjuntas. Por outro lado, houve também a saída de pessoas da 
empresa, mas permaneceu o relacionamento delas com integrantes de outras empresas. Isso ressalta que o relacionamento não pode ser encarado como tão somente uma escolha estratégica ou um recurso que pode ser transferido de um lado para o outro.

Outro ponto a ser ressaltado é o baixo nível de rotatividade das pessoas envolvidas no relacionamento como indicador de credibilidade, contribuindo para fortalecer a confiança. Identificou-se, ainda, que RIs mais próximos dão-se com empresas que internamente apresentam um bom relacionamento entre os funcionários (relacionamento intraorganizacional contribuindo para o RI). Os conflitos entre parceiros também surgiram como um fator de melhoria no relacionamento. No entanto, isso depende de como o conflito é encarado, construtivamente ou não. O relato a seguir revela alguns dos elementos apresentados:

\footnotetext{
"O índice de turnover sendo baixo, já começa a mostrar que a empresa é séria, então o cliente vê a empresa como confiável. Esse é o primeiro passo, tens que dar confiabilidade para varejo. A confiabilidade atrelada junto com o vendedor ..isso dá credibilidade. Confiança gera recompra, que gera a maturação e comprometimento do varejista e de nós também." (Entrevistado 3 - executivo de distribuidora de alimentos).
}

Como aspectos que desafiam o desenvolvimento do relacionamento, foram indicados a falta de uma política ou de comportamento de relacionamento claro por parte de algumas empresas, a insegurança em confiar, o oportunismo, os clientes pautados pelo menor preço e o problema da rotatividade. A falta de um comportamento claro associado ao relacionamento faz com que a empresa, tanto fornecedora quanto cliente, desenvolva suas práticas conforme as circunstâncias, o que indica inconsistência, reduz a credibilidade e aumenta a insegurança. A insegurança em confiar, que pode ter interferência de aspectos culturais organizacionais ou de experiências passadas, dificulta o desenvolvimento do relacionamento. Acrescenta-se a isso as resistências entre áreas de uma organização, com as respectivas diferenças nas formas de ver e interpretar as coisas, que podem acarretar problemas no desenvolvimento dos relacionamentos.

O oportunismo foi mencionado pelos entrevistados como um aspecto que não permite o fortalecimento do relacionamento pela insegurança que gera, principalmente em confiar. Os clientes pautados pelo menor preço também podem indicar a existência de um comportamento oportunista. A alta rotatividade, por sua vez, reduz as possibilidades de Revista Eletrônica de Estratégia \& Negócios, Florianópolis, v.14, n. 2, mai./ago. 2021. 
interações a médio e longo prazo, o que não permite conhecer os envolvidos com profundidade, desenvolver confiança e disposição a colaborar. As relações de poder surgem como desafio pelos efeitos derivados da influência de algumas pessoas sobre atividades, processos e outras pessoas.

\subsection{APRENDIZAGEM ORGANIZACIONAL (AO)}

Os resultados relativos à aprendizagem organizacional indicam a importância dos relacionamentos entre as áreas e entre os colegas dentro das organizações para o desenvolvimento ou reforço de conhecimentos, pontos de vista e habilidades. Além disso, revelam a predominância de aspectos e atividades de ordem informal.

A forma como pessoas de uma área busca conhecimento e se relacionam com outras áreas é um ponto fundamental para que se iniciem as interações. No entanto, o outro também precisa apresentar disposição. Isso pode ocorrer tanto entre pessoas de um mesmo nível organizacional como entre níveis diferentes, como o relato do executivo comercial que aprende com seus funcionários, mas também que os compreende melhor, assim como os clientes, quando resolvem um problema. Como indicam Antonello e Godoy (2010, p. 315), "[...] toda a atividade na vida dos indivíduos é uma oportunidade para aprendizagem."

O aprendizado de natureza cultural e a produção de novos significados ocorreram com a mudança de percepções dos indivíduos, advindas principalmente de suas experiências. 0 aprender novos pontos de vista, neste caso, dependeu dos níveis de interação entre os funcionários, incluindo os novos contratados, assim como contatos com pessoas de outras empresas. Ressalta-se o impacto do ingresso de determinadas pessoas que, com o apoio dos diretores, conseguiram gerar mudanças internas e melhorias no relacionamento com os clientes. Conforme o argumento de Lave e Wenger (1991), o aprendizado é dependente da atividade, contexto e cultura no qual ocorre ou se situa. O relato a seguir evidencia essa dependência:

\footnotetext{
“Dentro da empresa é o medo de compartilhar informações. Porque a informação é poder. Isso se vê nas coisas mais básicas. Um funcionário não quer ensinar outro funcionário com medo de perder o poder. As pessoas não conversam muito, existem falhas de comunicação entre os departamentos. As empresas continuam tendo feudos que são os principais entraves." (Entrevistado 4 - consultor de marketing).
} 
Ficou evidente a predominância dos processos e atividades informais de aprendizagem. Identificou-se, ainda, que os processos formais não estão desvinculados dos informais, dependem dos informais e podem servir como estímulo à aprendizagem informal. A aprendizagem informal ocorreu tanto em situações informais quanto formais, tais como na resolução de um problema operacional ou na discussão suscitada a partir de conceitos apresentados em um treinamento. Conforme relato, o desenvolvimento de uma dinâmica de grupo permitiu a aproximação de pessoas que não se falavam ou se conheciam pouco, permitindo troca de ideias e outras interações posteriormente.

\footnotetext{
"Existem casos de pessoas que aqui dentro só se comunicavam por causa do trabalho. A partir dos treinamentos e das dinâmicas que estabelecemos, onde eles discutiram problemas, mais as visitas aos departamentos, hoje eles entendem os problemas, seus e dos outros, de forma diferente. Principalmente nas atividades que foram feitas em conjunto, as pessoas começam conhecendo um pouco mais das outras." (Entrevistado 5 - executivo fornecedora de componentes para móveis).
}

Outros aspectos identificados nos relatos dos entrevistados estão associados ao "entrar no ritmo", ao trabalhar em várias funções e aos níveis de burocracia. O "entrar no ritmo" indica o nível de aprendizado de determinado indivíduo, que ocorre a partir da geração, disseminação e interpretação de conhecimentos, experiências e percepções. Além disso, a possibilidade de trabalhar em várias funções permitiu ampliar o repertório de experiências, conhecimentos e percepções, o que assegura melhor preparo para entender o todo, trocar ideias e apresentar argumentos e comportamentos convincentes e consistentes aos outros. Já a importância de desburocratizar surgiu pela necessidade de tornar o processo de aprendizagem mais fluido. Os entrevistados mencionam que a excessiva burocracia, principalmente em grandes empresas, dificulta a aprendizagem. Ou seja, aspectos formais, neste caso, interferem de maneira negativa na $A O$, na qual predominam processos $e$ atividades informais, resultado também identificado por Janowicz-Panjaitana e Noorderhavenb (2008).

Em síntese, salientam-se como características da AO: a importância dos relacionamentos intraorganizacionais; o ingresso de novas pessoas e mudanças em alguns aspectos culturais; o aprender novos pontos de vista; a predominância dos processos informais de aprendizagem; os processos formais indissociáveis dos processos informais; a aprendizagem que ocorre em situações informais de resolução de problemas; o "entrar no ritmo"; a importância de desburocratizar para facilitar o aprendizado. Revista Eletrônica de Estratégia \& Negócios, Florianópolis, v.14, n. 2, mai./ago. 2021. 


\subsection{APRENDIZAGEM INTERORGANIZACIONAL (AI)}

Em se tratando de Al, Knight (2002) a define como a aprendizagem no contexto de grupos ou pares de organizações que estão proativamente cooperando. No Quadro 1 apresenta-se um resumo dos resultados.

Quadro 1 - Características da Aprendizagem Interorganizacional

\begin{tabular}{|c|c|}
\hline Categorias & Características \\
\hline $\begin{array}{l}\text { Situações de } \\
\text { Aprendizagem } \\
\text { Interorganiza } \\
\text { cional }\end{array}$ & $\begin{array}{l}\text { - } \text { aprendizagem entre fornecedor e cliente, e vice-versa; } \\
\text { - importância da trajetória dos envolvidos e de seus repertórios de conhecimentos, } \\
\text { - imperiências e percepções acumulados (memória); } \\
\text { - } \text { aprendizagens; } \\
\text { - feiras, eventos e convenções de vendas como locais férteis para aprendizagem } \\
\text { informal; } \\
\text { - aprendizado com as visitas entre parceiros. }\end{array}$ \\
\hline $\begin{array}{l}\text { Processos de } \\
\text { aprendizagem } \\
\text { (formal e } \\
\text { informal) }\end{array}$ & $\begin{array}{l}\text { - } \text { predominância do processo informal; } \\
\text { - contribuição dos processos informais para resultados formais de aprendizagem; } \\
\text { - contribuição dos processos formais para resultados informais de aprendizagem; } \\
\text { - importância da trajetória dos indivíduos; } \\
\text { - maturidade e insegurança; } \\
\text { - } \quad \text { aprender a confiar, a se comprometer e a cooperar para continuar no negócio ou } \\
\text { para melhorar o relacionamento. }\end{array}$ \\
\hline $\begin{array}{c}\text { Confiança e } \\
\text { aprender a } \\
\text { confiar }\end{array}$ & $\begin{array}{l}\text { - confiança que se conquista e que já faz parte da rotina; } \\
\text { - ficar à disposição do cliente, querer auxiliá-lo a resolver problemas com indicativo } \\
\text { - clientes buscando sugestões de fornecedor para um produto deles (confiança em } \\
\text { buscar); } \\
\text { - transparência, conhecimento e seriedade facilitam a confiança } \\
\text { - contrato pode ajudar a aumentar a confiança, ou serve para reduzir a insegurança } \\
\text { - inicial, dar condições da confiança se desenvolver; } \\
\text { - } \text { marca tradicional como um ponto de referência para confiar; } \\
\text { - fortalecimento de confiança a partir de algum abalo nela; } \\
\text { - rotatividade de pessoal como barreira para aprender a confiar. }\end{array}$ \\
\hline $\begin{array}{c}\text { Dificuldades na } \\
\text { Aprendizagem } \\
\text { Interorganiza } \\
\text { cional }\end{array}$ & $\begin{array}{l}\text { - não conhecer bem o parceiro; } \\
\text { - falta de abertura; } \\
\text { - falta de humildade; } \\
\text { - falta de confiança; } \\
\text { - comportamento oportunista; } \\
\text { - carência de interação entre funcionários de empresas diferentes; } \\
\text { - desafio de mudar os pressupostos, as visões de mundo. } \\
\text { - rotatividade de pessoal. }\end{array}$ \\
\hline
\end{tabular}

Fonte: Elaborado pelos autores, 2021.

$\mathrm{Na}$ Al surgem situações que ocorrem entre os fornecedores e clientes, e vice-versa. Neste caso, identificaram-se empresas dispostas a aprender com o fornecedor, e não simplesmente o contrário, no que tange à compreensão das necessidades do mercado. Revista Eletrônica de Estratégia \& Negócios, Florianópolis, v.14, n. 2, mai./ago. 2021. 
Conforme relatos, o cliente conseguiu compreender melhor suas necessidades e processo, assim como atender melhor os consumidores e aprimorar o relacionamento, a partir de aprendizados com o fornecedor, tanto por observação, imitação e exemplos de pessoas como referências, quanto por discussões e questionamentos conjuntos; o fornecedor auxiliou o cliente a compreender-se melhor.

\footnotetext{
"No contato com os fornecedores A e B, eles nos deram muita abertura. Eles abrem o laboratório deles para a gente fazer testes, acompanham. Quando tem desenvolvimento do produto a gente passa as informações, interage com eles. 0 aprendizado disso é no dia a dia. Tu assim acabas aumentando a proximidade com eles, tu acabas te tornando uma referência em alguns casos, em alguns aspectos, quando determinadas situações acontecem." (Entrevistado 5 - executivo fornecedora de componentes para móveis).
}

Por outro lado, os ensinamentos tanto dos fornecedores quanto dos clientes reverteram para aprendizado das empresas dos entrevistados (inclusive a melhor compreensão do que está sendo ensinado). Retoma-se, em relação a isso, que com melhor conhecimento dos fornecedores e clientes melhoram a escolha de produto e a satisfação de suas necessidades, fortalecendo o desempenho do relacionamento (ALTINAY; BROOKES, 2012; CHANG; GOTCHER, 2010; LAI et al., 2009).

\footnotetext{
"Visão de mercado, o contato direto com o cliente na ponta. É trabalho diretamente com o consumidor, trabalha os anseios, traz um preparo. Hoje o mercado puxa a indústria, hoje não é ter o foco no cliente e sim assumir o foco do cliente. Tua indústria com olhos de cliente. Claro que tem a visão industrial, tem que conciliar." (Entrevistada 6 - executiva de empresa fornecedora de componentes para o lar).
}

Outro aspecto tem relação com os repertórios de conhecimentos tácitos e explícitos, oriundos tanto de processos de exploração (exploration) quanto de utilização (exploitation). Por um lado, experiências em outras empresas, conhecimentos e percepções de indivíduos interferiram em suas atividades atuais. Um exemplo é o executivo de distribuição cujo aprendizado de empregos passados em empresas fornecedoras lhe permitiram se relacionar melhor, agora como distribuidor, com empresas fornecedoras da atual distribuição. Por outro lado, há o conhecimento organizacional prévio que facilita a relação posterior com os clientes. Um exemplo é com a empresa de serviços financeiros que aproveitou seus conhecimentos, experiências e procedimentos de gestão para aprimorar as competências de seus intermediários. Isso não elimina a contribuição do cliente, nesse caso: 
conhecíamos gestão. Mostrar que em conjunto nós podíamos transformar algumas coisas. Aprendemos com eles a simplificar as coisas. Nosso modelo é esse, a gente acaba aprendendo junto com eles." (Entrevistado 1 - executivo de empresa de serviços financeiros).

Como locais de aprendizagem, tendo em vista as práticas do marketing de relacionamento, foram indicados feiras, eventos, convenções e espaços para exposição e as visitas a clientes e a fornecedores. No caso das feiras, eventos, convenções e espaços para exposição (como show rooms), identificaram-se como locais férteis para aprendizagem, principalmente a informal: pessoas que dificilmente se encontrariam em outras situações têm a oportunidade de interagir e compartilhar ideias.

\begin{abstract}
“A empresa pró-ativa ouve o que não estão dizendo. É como se ela tivesse um radar de sinais. Ela olha para os sinais fortes, assim como os sinais fracos. Em mercados onde ela atua e nos quais ela não atua. Exemplo, as empresas de móveis têm que aprender com a indústria da moda. Assim como a Empresa X pode captar sinais lá no São Paulo Fashion Week. Isso é um aprendizado numa empresa pró-ativa, um aprendizado não convencional." (Entrevistado 4 - consultor de marketing).
\end{abstract}

Com as visitas, quer seja a um intermediário ou a um cliente final, acompanhando um vendedor ou visitando um fornecedor, consegue-se, como indicou um entrevistado, "sentir melhor o mercado", marcar presença, fortalecer a credibilidade, aprender novas formas de ver o mundo ou compreender melhor outros pontos de vista. Podem-se ampliar os conhecimentos não apenas dos fornecedores, mas também dos clientes.

\footnotetext{
"Acerto com a franquia uma visita a determinada pessoa, mas demora uma hora para chegar a ele. $\mathrm{O}$ consultor da franquia, estando no meu lado, conversando, tu vais reparando nele. É o aprendizado na conversa do dia a dia, no almoço, no bate papo, parece que assim a pessoa está mais desarmada." (Entrevistado 1 - executivo de empresa de serviços financeiros).
}

Do lado dos fornecedores, funcionários de outras áreas que não têm maior contato com o cliente conseguem entender melhor as áreas de maior contato, facilitando o relacionamento intra e interorganizacional. Mesmo os que não visitaram aprendem com os que visitaram, que disseminam o que viram e aprenderam. Em relação a isso, conforme relato, a área comercial possibilita o contato das outras áreas com outras empresas. Do lado dos clientes, informações prestadas, experiências passadas e práticas atuais podem servir como referência, permitindo também melhoria no relacionamento. Isso corrobora o que foi apresentado por Selnes e Sellis (2003), para quem a aprendizagem do relacionamento envolve histórias comuns, esquemas de referência e valores das duas partes, que podem ser diferentes 
dentro das organizações envolvidas, podendo tanto receber contribuições da AO como contribuir com ela.

\begin{abstract}
"O fato de algumas áreas não estarem envolvidas direto com o mercado, elas acham que o jeito como elas fazem é o certo. Já foi pior. Porque hoje a gente busca da seguinte forma: quando a área comercial viaja, o responsável da área industrial, o cara dos projetos, de engenharia ... a gente leva todos para conhecer o cliente, para entender como funcionam as coisas na frente do cliente. Ao voltarem, eles falam com as outras pessoas." (Entrevistado 5 - executivo fornecedora de componentes para móveis).
\end{abstract}

No que tange aos processos de aprendizagem, tal como dentro das organizações, o informal predominou também entre as organizações. Situações que são facilitadas quando a pessoa, como indicou um entrevistado, está "desarmada". Também foi citado o aprender através do olho no olho, dos exemplos, do jeito de ser (cultura). No entanto, importante ressaltar que esse aprendizado informal será mais efetivo em relacionamentos de qualidade, com interações frequentes e que transmitem segurança. Há também a situação do aprendizado formal recebendo contribuições e sendo alavancado por resultados advindos de processos informais de aprendizagem, ou seja, tal como identificado na $\mathrm{AO}$, que o formal não está separado do informal. Relativo a isso, retomando o que foi identificado por JanowiczPanjaitana e Noorderhavenb (2008), comportamentos informais no contexto interorganizacional apresentam efeito consistentemente positivo nos resultados da aprendizagem e nos comportamentos de aprendizagem formal.

\footnotetext{
"Tens que ouvir o que vem da ponta, do cliente, mas tem que saber filtrar, caso contrário não se faz nada. Mas a gente aprende muito com eles, no dia a dia... a gente aprende a mudar o nosso modelo. A vivência é muito forte. Tu dás a base com treinamento, mas a vivência te molda." (Entrevistado 1 - executivo de empresa de serviços financeiros).

“Os clientes aprendem com a gente não só na mudança na forma de ver as coisas, mas ratifica alguns pontos de vista. Eles também aprendem a melhorar suas práticas a partir das nossas práticas." (Entrevistada 6 - executiva de empresa fornecedora de componentes para o lar).

“A relação de aprendizagem acontece entre eles (funcionários de clientes). E não é somente no momento do treinamento. A maior repercussão é no dia posterior. No sentido de cobrança entre eles. Por que o cara deixa de vender no dia seguinte, se ele teve a mesma informação que os outros? Então o gerente começa a cobrar eles, dizendo: antes vocês não vendiam porque não tinham informação, mas agora têm." (Entrevistado 7 - representante comercial)
}

Como indicou um entrevistado, o relacionamento depende de empresa com maturidade. Essa maturidade está relacionada à redução da insegurança em se integrar com Revista Eletrônica de Estratégia \& Negócios, Florianópolis, v.14, n. 2, mai./ago. 2021. 
outras empresas. Em função disso, para empresas que resolvem entrar em um RI, mas não estão muito seguras a respeito disso, podem aprender a confiar, a se comprometer e a cooperar quanto percebem a necessidade de mudança, de assumir efetivamente o relacionamento.

Em relação à confiança e ao aprender a confiar, um ponto bastante presente nas entrevistas, primeiramente identificou-se o processo de conquista da confiança, e os respectivos aprendizados associados, até o momento em que a confiança faz parte da rotina, ou seja, quando não se pensa mais se há confiança entre as partes ou no quanto se confia no outro ou que são se pensa mais se confia ou não e quanto confia.

A confiança desenvolve-se através de ações e comportamentos de ambas as partes, como ficar à disposição do cliente, querer auxiliá-lo a resolver problemas, o próprio cliente buscar sugestões com o fornecedor para melhorias em seus produtos e processos (confiança em buscar ajuda, não somente confiar porque foi amparado). Como indicou um entrevistado, merecer a confiança de alguém. No entanto, há a necessidade de a confiança encontrar um campo fértil para se desenvolver, o que requer, além da existência de transparência, conhecimento e seriedade, a disposição a confiar, mesmo que esta não ocorra nas primeiras interações do relacionamento. Em alguns casos, a confiança já está presente antes de iniciar o relacionamento, em decorrência de marcas de credibilidade presentes nos negócios envolvidos.

\footnotetext{
"Vai crescendo (a confiança) com o tempo nas empresas com quem você tem relação de confiança. Porém, nas empresas onde há uma relação de desconfiança, eu diria que decresce, mas é muito difícil. Ficam aquelas perdas no caminho e se torna difícil de transpor. Mas nas que há uma proatividade de ambas, em trabalhar em conjunto e transparência, nas que a gente estabelece confiança, a confiança só cresce." (Entrevistado 2 - executivo de prestadora de serviços de saúde).
}

Por outro lado, o contrato, como um mecanismo de governança, pode auxiliar no aumento da confiança, mesmo que se pressuponha que a existência desse mecanismo pode ser um sinal de falta de confiança. O contrato pode servir para reduzir a insegurança inicial e dar condições da confiança se desenvolver, como se fosse uma garantia contra o comportamento oportunista. No entanto, há a necessidade de uma frequência de interações e repetição de ações para que a confiança cresça. 
Surgiu também das entrevistas o aprender a desconfiar. Em função de comportamentos ou ações repetidas que indicam um comportamento oportunista, um dos parceiros pode começar a aprender a desconfiar, mesmo que não pretendesse inicialmente, o que por sua vez abalará a confiança existente e, em consequência, o relacionamento como um todo. No entanto, um dos parceiros pode, em função de um abalo na confiança, aproveitar a situação para fortalecê-la, como comportamentos que mereçam uma chance, um voto de confiança.

Além disso, assim como surgiu nas análises anteriores, a rotatividade de pessoal também surge como barreira para o aprender a confiar. Paralelamente, o lado negro da confiança, ou seja, a confiança em nível elevados sendo prejudicial ao relacionamento (SELNES; SALLIS, 2003; YANG; LAI, 2012), não chegou a ser abordado pelos entrevistados, o que indica a percepção positiva da relação entre confiança e relacionamento.

Por fim, como dificuldades na aprendizagem, todas estão associadas ao desafio em assumir efetivamente o relacionamento, como confiar mais, abrir-se mais, demonstrar falta de humildade, não conhecer bem o parceiro, apresentar comportamento oportunista, não conseguir alterar a forma como enxerga e interpreta o mundo. Importante destacar nesses itens a falta de humildade, ou o excesso de arrogância, elementos que bloqueiam o processo de aprendizagem, pelos envolvidos considerarem a necessidade de não aprender. A aprendizagem, neste caso, não é uma via de mão dupla.

\footnotetext{
“Então tu precisas das pessoas para dar resultado. Nós temos que lidar com a capacitação das pessoas, principalmente pelo tipo de serviços que vendemos. Nós temos que nos desenvolver, e isso foi um grande aprendizado. Primeiro aprende a lidar com canais de distribuição próprios, depois nós tivemos que ser humildes em saber que nós não sabíamos tudo e aprender isso. Daí começamos a dar passos mais largos." (Entrevistado 1 - executivo de empresa de serviços financeiros).
}

Isso pode ser devido, dentre outras coisas, à empresa ainda não estar preparada para se relacionar com outra, ou apenas tratar o relacionamento como tão somente uma escolha estratégica, dependente predominantemente de aspectos racionais e formais. Também há o problema da rotatividade de pessoal, que pode afetar empresas dispostas a se relacionar com outras. Nesse contexto, o que deve ser avaliado é se predomina a rotatividade derivada de uma influência externa à empresa ou em função de uma característica interna. Quanto a isso, com base em Ballantyne (2004), alerta-se que a existência de um ambiente de aprendizagem Revista Eletrônica de Estratégia \& Negócios, Florianópolis, v.14, n. 2, mai./ago. 2021. 
intra e interorganizacional depende da disposição dos gestores em permitir e apoiar determinadas ações, face ao que pode apresentar resultados incertos.

\subsection{PROPOSIÇÃO DE UM ESQUEMA CONCEITUAL}

Conforme os achados, fica evidente a natureza processual da aprendizagem, com a preponderância de processos informais, estando presentes o aprendizado a partir de observações e experiências, trocas, discussões e resultados. Destaca-se que as partes de um relacionamento podem legitimar consensualmente algumas experiências interorganizacionais compartilhadas, permitindo sua internalização pelos membros envolvidos e gerando variedade às suas experiências (HOLMQVIST, 2003). A partir disso, elaborou-se um esquema conceitual, baseado nos achados do estudo (Figura 1)

Figura 1 - Esquema conceitual

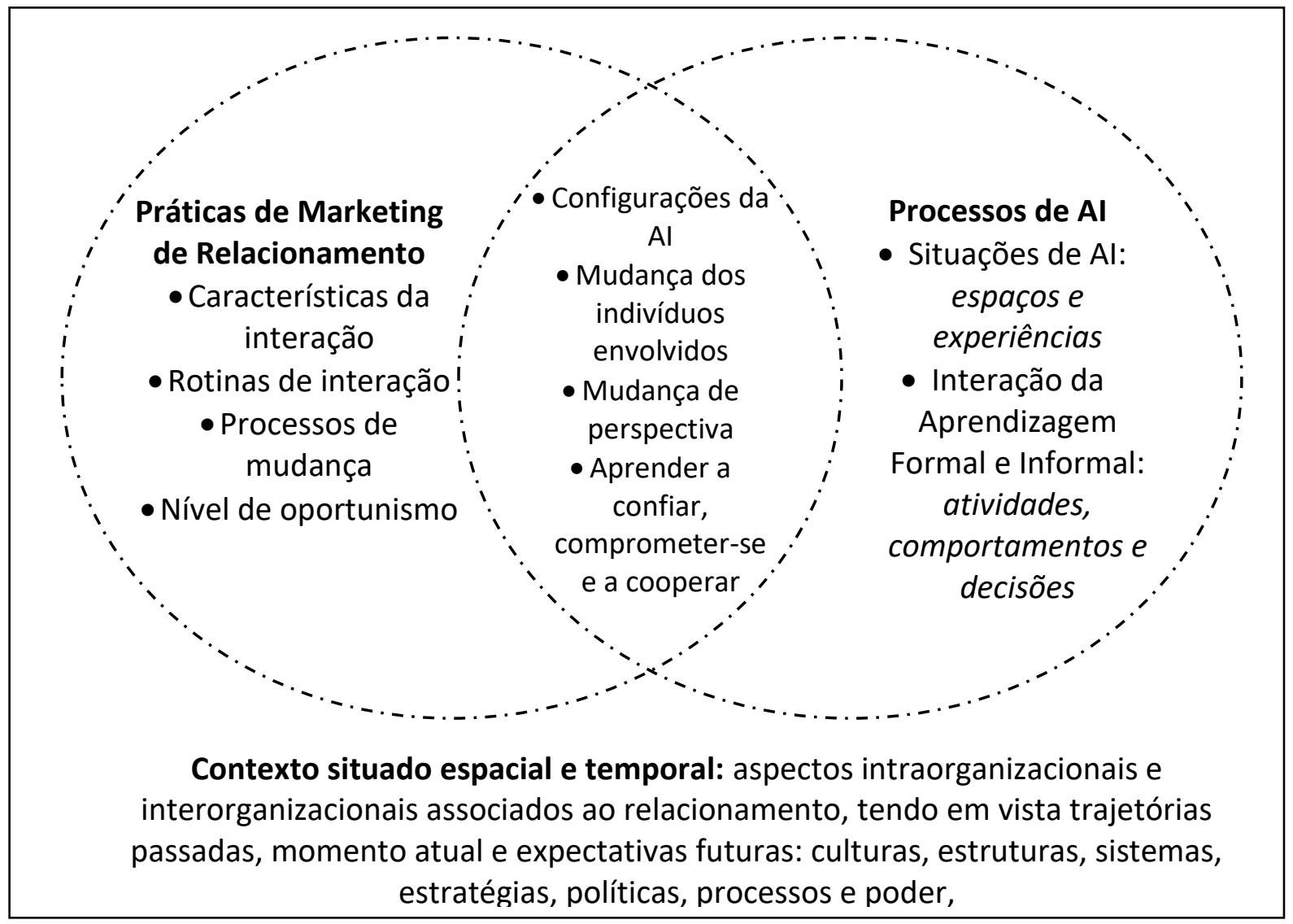

Fonte: Elaborado pelos autores, 2021.

O esquema é apresentado graficamente por elipses tracejadas (macrocategorias) que interagem entre si, tendo um contexto que as envolve. Os tracejados, de diferentes aberturas, servem para simbolizar a permeabilidade das elipses em relação ao contexto. Numa elipse 
temos a macrocategoria práticas de marketing de relacionamento, representadas pelas categorias "características da interação", "rotinas de interação", "processos de mudança" e "nível de oportunismo", baseadas nos resultados apresentados na seção 4.1. Na elipse (macrocategoria) processos de $\mathrm{Al}$ tem-se as categorias "situações de $\mathrm{Al}$ " (espaços e trajetórias) e "interação da aprendizagem formal e informal" (atividades, comportamentos e decisões), baseadas nos resultados das seções 4.2 e 4.3 .

$\mathrm{Na}$ intersecção das elipses temos as categorias resultantes da interação entre as práticas de marketing de relacionamento e os processos de Al: "configurações da Al", tendo em vista as possibilidades de arranjos e constituições de aprendizagem advindos das interações, dos espaços e das experiências; "mudanças dos indivíduos", tendo como referência os níveis de rotatividade, que podem afetar tanto de forma negativa quanto positiva a aprendizagem, dependendo dos seus níveis; "mudanças de perspectiva", associados às visões de mundo, elementos simbólicos e de gestão; "aprender a confiar, comprometer-se e a cooperar", tendo em vista os elementos centrais das práticas de marketing de relacionamento alinhavando-se com os processos de Al. Optou-se, em relação a isso, por não fazer menção apenas ao aprender a confiar como categoria, uma vez que havia suporte dos achados e para salientar seu papel na relação com comprometimento e cooperação, elementos centrais do marketing de relacionamento (PALMATIER et al., 2006; LARENTIS; ANTONELLO; SLONGO, 2018).

Em volta dessas elipses tem-se o contexto situado espacial e temporal, com vistas elementos advindos da interação entre aspectos intraorganizacionais e interorganizacionais com dimensões relativas ao passado, presente e futuro (LARENTIS et al., 2014; NONAKA; TOYAMA; HIRATA, 2011). Optou-se por considerar o contexto espacial e temporal em conjunto, uma vez que os elementos associados a culturas, estruturas, sistemas, estratégias, políticas, processos e poder não se dissociam de ambos os aspectos. Tanto as elipses tracejadas, suas interações entre si e com o contexto levam em consideração a lógica da aprendizagem situada e das práticas

Práticas são as formas de fazer de uma sociedade, emergem do emaranhamento de fazer e saber (doing e knowing) e relacionam-se com a construção e a reprodução social, com os processos de aprendizagem e de geração de conhecimento no contexto de um grupo Revista Eletrônica de Estratégia \& Negócios, Florianópolis, v.14, n. 2, mai./ago. 2021. 
determinado, tendo a repetição de atividades como estabilização e legitimação (BISPO, 2013; GHERARDI, 2014). Em função disso, a noção de prática é rica à medida que articula a noção de espaço-tempo do fazer dos atores, isto é, de práticas situadas, implicando incertezas, conflitos e incoerências como características intrínsecas a essas práticas, possibilitando consideráveis insights e contribuindo para a compreensão da dinâmica de uma organização, bem como para o fluxo de mudança em um sistema social (ANTONELLO; GODOY, 2010).

Nesse sentido, o esquema conceitual ratifica a aprendizagem como um fenômeno predominantemente cultural e social (ANTONELLO; GODOY, 2010; GHERARDI, 2005; NICOLINI; GHERARDI; YANOW, 2003). Em tratando-se de aprendizagem interorganizacional, por depender de RIs e da formação de confiança (HOLMQVIST, 2003), fica evidente a importância de considerar as configurações das interações entre os indivíduos envolvidos, o que inclui o aprender a confiar. Além disso, deve-se ter em mente as dificuldades que podem interferir nessas configurações, como a rotatividade de pessoal, principalmente a dos interfaceadores, assim como os níveis de oportunismo, tendo em vista um contexto no qual o poder também faz parte.

Os resultados reforçam, ainda, que o desenvolvimento dos principais elementos constituintes dos relacionamentos entre fornecedores e clientes, como confiança, comprometimento e cooperação (MORGAN; HUNT, 1994; MORGAN, 2000; PALMATIER et al., 2006), a partir das práticas do marketing de relacionamento, são dependentes muito mais das interações sociais, principalmente dos funcionários interfaceadores, originadas dos relacionamentos interpessoais do que de processos formais de aprendizagem.

Especificamente quanto aos indivíduos envolvidos nos relacionamentos, convém destacar os achados relacionados às mudanças de pontos de vista em função de interações com novos empregados ou com pessoas de outras empresas. Em relação a isso, a possibilidade dos interfaceadores serem mais bem compreendidos por indivíduos de outras áreas organizacionais, quando estes possuem oportunidade de interagir com os clientes, como em feiras, visitas ou projetos conjuntos, indica o que poderia ser nominado como momento de "interface interorganizacional", onde a Al contribui para a AO. Ou então a possibilidade de incluir novas visões de mundo com a contratação de novos funcionários: um momento de 
“interface organizacional" onde a AO poderá contribuir com a Al. Convém destacar que os momentos de "interface" remetem à noção de fronteiras organizacionais (HALLEY, 1998).

Nesse estudo ratifica-se o que foi considerado por Turley e Geiger (2006) como pressupostos da aprendizagem interorganizacional. Ou seja, pode ser encarada como algo pessoal, se desenvolve preponderantemente pela ação, é contextual e, portanto, situada, envolve ritmo e esquema de interações sociais, está em aberto e apresenta tanto fatores tácitos quanto explícitos. Tais pressupostos são evidenciados e ampliados no esquema conceitual, considerando a interação entre as práticas do marketing de relacionamento e os processos de aprendizagem interorganizacional, dependentes das características e rotinas de interação, das situações e processos de aprendizagem formal e informal e dos processos de mudança, atrelados às configurações espaciais e temporais do contexto.

\section{CONSIDERAÇÕES FINAIS}

Estratégias associadas a RIs envolvem processos de interação e engajamento para desenvolver e manter relacionamentos cooperativos de longo prazo. No entanto, para Winklhofer, Pressey e Tzokas (2006), os benefícios dos Rls dependerão do quanto estes são valorizados nos níveis organizacionais e enraizados nas culturas organizacionais. Isso inclui os processos de aprendizagem, inclusive em nível interorganizacional.

O processo de aprendizagem é influenciado pela demora em se desenvolver o relacionamento, portanto dependente de questões referentes à confiança, ao comprometimento e à cooperação (HARDY; PHILLIPS; LAWRENCE, 2003; LANE, 2001). Neste aspecto, ligações mais próximas e estáveis, particularmente em relacionamentos baseados na confiança, encorajam maior abertura para aprender (LANE, 2001). Assim, objetivou-se neste estudo analisar os processos de aprendizagem advindos dos RIs, com foco nas práticas do marketing de relacionamento.

Os resultados do estudo permitem afirmar que a aprendizagem interorganizacional, no tocante às estratégias dos RIs, mais especificamente às práticas do marketing de relacionamento, acontece de forma situada e predominantemente de maneira informal, reconhecendo os indivíduos e grupos envolvidos, as interações vendedor-cliente (inclusive suas histórias) e as questões políticas e de poder, muito presentes nesta área da organização Revista Eletrônica de Estratégia \& Negócios, Florianópolis, v.14, n. 2, mai./ago. 2021. 
que lida com as relações com os mercados. Nesse ínterim, situar significa envolver indivíduos, o ambiente e as atividades para criar significado (ANTONELLO, 2011). Além disso, fica clara a necessidade de se considerar atividades que facilitem a Al e suas respectivas trocas (NEMBHARD; 2012).

Deve-se ter em mente, então, que para se avançar nas estratégias de relacionamento surge a necessidade do aprender a confiar, comprometer-se e, portanto, a cooperar, o que ocorre principalmente de maneira informal e tácita, por meio das interações, através dos interfaceadores, as quais se consolidam a longo prazo. A rotatividade de pessoal também surge como um desafio. Complementarmente, deve-se levar em conta o que se chama de "lado negro da confiança" (SELNES; SALLIS, 2003; YANG; LAI, 2012), mesmo que neste estudo não tenham surgido evidências a respeito.

Sendo assim, como revelado pelo esquema conceitual proposto, considerar nas estratégias e práticas dos Rls a aprendizagem situada e de nível interorganizacional implica compreender melhor os contextos, os microprocessos e as práticas dos atores envolvidos, principalmente dos interfaceadores. Com base nos resultados e indicações de Larentis et al. (2014), o presente estudo reforça a consideração à aprendizagem situada, em nível interorganizacional, como um referencial valioso para o aprofundamento da compreensão das dimensões, estratégias e práticas associadas aos Rls, de forma geral, e ao marketing de relacionamento, de maneira específica.

Em se tratando do papel dos interfaceadores, as organizações deveriam estar atentas à maneira como eles aprendem, tendo em vista suas idiossincrasias e dificuldades, e de que maneira poderiam oportunizar e estruturar um ambiente organizacional favorável à aprendizagem, considerando visitas, viagens, mentorias, trabalhos conjuntos, treinamentos formais e aprendizado com erros. Deveriam, neste sentido, levar em consideração e incentivar as oportunidades de compartilhamento de conhecimentos tácitos e explícitos na aprendizagem formal e de interação com indivíduos das diversas áreas organizacionais e de outras empresas, os momentos de interface.

Como limitações do estudo, foram entrevistadas principalmente pessoas ligadas a fornecedores: a entrevista com pessoas ligadas a empresas clientes poderia agregar novas 
nuanças ou perspectivas. Por outro lado, aspectos ligados ao poder e ao "lado negro da confiança" foram tratados superficialmente. Como sugestão para futuros estudos, considerando os achados do presente estudo e as indicações de Antonello e Godoy (2010), relacionadas aos níveis de aprendizagem, neutralidade da meta, noção de mudança e natureza processual, poder-se-ia analisar com maior profundidade como interagem os níveis de aprendizagem grupal, intergrupal, organizacional e interorganizacional nas práticas dos relacionamentos, incluindo os contextos do poder. Recomenda-se também aprofundar o entendimento do "lado negro da confiança" em situações de aprendizagem.

\section{REFERÊNCIAS}

ALTINAY, L.; BROOKES, M. Factors influencing relationship development in franchise partnerships. Journal of Services Marketing, v. 26, n. 4, p. 278 - 292, 2012.

ANTONELLO, C. S. Saberes no Singular? Em discussão a falsa fronteira entre a aprendizagem formal e informal. In: ANTONELLO, C. S. et al. Aprendizagem organizacional no Brasil. Porto Alegre: Bookman, 2011. p. 225-245

ANTONELLO, C. S.; GODOY, A. S. A encruzilhada da aprendizagem organizacional: uma visão multiparadigmática. Revista de Administração Contemporânea, v. 14, p. 310-332, 2010.

BADIR, Y. F.; O'CONNOR, G. C. The formation of tie strength in a strategic alliance's first new product development project: The influence of project and partners' characteristics. Journal of Product Innovation Management, v. 32, n. 1, p. 154-169, 2015.

BALLANTYNE, D. Dialogue and its role in the development of relationship specific knowledge. Journal of Business \& Industrial Marketing, v. 19, n. 2, p. 114-123, 2004.

BARROSO-MÉNDEZ, M. J.; GALERA-CASQUET, C.; VALERO-AMARO, V. Proposal of a social alliance success model from a relationship marketing perspective: a meta-analytical study of the theoretical foundations. BRQ Business Research Quarterly, v. 18, n. 3, p. 188-203, 2015.

BELLE, S. Organizational learning? Look again. The Learning Organization, v. 23, n. 5, p.332341, 2016.

BISPO, M. S. Aprendizagem organizacional baseada no conceito de prática: contribuições de Silvia Gherardi. RAM. Revista de Administração Mackenzie, v. 14, n. 6, p. 132-161, 2013.

BOUNCKEN, R. B.; PESCH, R.; KRAUS, S. SME innovativeness in buyer-seller alliances: effects of entry timing strategies and inter-organizational learning. Review of Managerial Science, v. 9, n. 2, p. 361-384, 2015.

BROWN, J. S.; DUGUID, P. Knowledge and organization: a social-practice perspective.

Organization Science, v. 12, n. 2, p. 198-213, Apr. 2001. 
CHANG, K.; GOTCHER, D. F. Conflict-coordination learning in marketing channel relationships: distributor view. Industrial Marketing Management, v. 39, p. 287-297, 2010

CHILD, J. Learning through Strategic Alliances. In: DIERKES, M. et al. Organizational learning and knowledge. Oxford: Oxford University Press, 2001.

COUGHLAN, A. T. et al. Canais de marketing. 7. ed. São Paulo: Pearson, 2012.

ESTIVALETE, V. F. B.; PEDROZO, E. A. From Individual Learning to Interorganizational Learning: Proposition of an Analysis Framework. Desenvolvimento em Questão, v. 16, n. 43, p. 45-76, 2018.

FANG, S-R. et al. Relationship learning and innovation: The role of relationship-specific memory. Industrial Marketing Management, v. 40, p. 743-753, 2011

GEYSKENS, I.; STEENKAMP, J.; KUMAR, N. A meta-analysis of satisfaction in marketing channel relationships. Journal of Marketing Research, v. 36, n. 2, p. 223-238, May 1999.

GHERARDI, S. Organizational knowledge: the texture of workplace learning. London: Blackwell, 2005.

GHERARDI, S. Conhecimento situado e ação situada: o que os estudos baseados em prática prometem? In: GHERARDI, S.; STRATI, A. (org.). Administração e aprendizagem na prática. Rio de Janeiro: Elsevier, 2014. p. 3-17

GIBB, J.; SUNE, A.; ALBERS, S. Network learning: Episodes of interorganizational learning towards a collective performance goal. European Management Journal, v. 35, n. 1, p. 15-25, 2017.

GUMMESSON, E. Marketing de relacionamento total. 3. ed. Porto Alegre: Bookman, 2010.

GUMMESSON, E. From relationship marketing to total relationship marketing and beyond. Journal of Services Marketing, v. 31, n. 1, p. 16-19, 2017.

GUNDLACH, G. T.; CANNON, Joseph P. "Trust but verify"? The performance implications of verification strategies in trusting relationships. Journal of the Academy of Marketing Science, v. 38, n. 4, p. 399-417, 2010

HÅKANSSON, H.; SNEHOTA, I. Developing relationships in business networks. London: Routledge, 1995.

HALLEY, A. A. Applications of boundary theory to organizational and inter-organizational culture. Public Administration and Management, v. 3, n. 2, p. 1-14, 1998.

HARDY, C.; PHILLIPS, N.; LAWRENCE, T. Resources, knowledge and influence: the organizational effects of interorganizational collaboration. Journal of Management Studies, v. 40, n. 2, p. 321-347, 2003, Mar. 2003.

HOLMQVIST, M. A dynamic model of intra-and interorganizational learning. Organization Studies, v. 24, n. 1, p. 95-123, 2003. 
HUELSMANN, M.; LOHMANN, J.; WYCISK, C. The Role of Inter-organizational Learning and Self-organizing Systems in Building a Sustainable Network Culture. International Journal of Knowledge, Culture and Change Management, v. 5, n. 2, p. 21-30, 2006.

IMRAN, M. K.; ILYAS, M.; ASLAM, U. Organizational learning through transformational leadership. The Learning Organization, v. 23, n. 4, p. 232-248, 2016.

JANOWICZ-PANJAITANA, M; NOORDERHAVENB, N. G. Formal and informal interorganizational learning within strategic alliances. Research Policy, v. 37, p.1337-1355, 2008.

KANG, B.; JINDAL, R. P. Opportunism in buyer-seller relationships: Some unexplored antecedents. Journal of Business Research, v. 68, n. 3, p. 735-742, 2015.

KNIGHT, L. Network learning: exploring learning by interorganizational networks. Human Relations, v. 55, n. 4.p. 427-454, 2002.

KULL, T. J.; ELLIS, S. C. Coping with dependence: a logistics strategy based on interorganizational learning for managing buyer-supplier relations. Journal of Business Logistics, v. 37, n. 4, p. 346-363, 2016.

LAI, C. et al. The effects of market orientation on relationship learning and relationship performance in industrial marketing: The dyadic perspectives. Industrial Marketing Management, v. 38, n. 2, p. 166-172, 2009.

LANE, C. Organizational learning in supplier networks. In: DIERKES, M. et al. Organizational learning and knowledge. Oxford: Oxford University Press, 2001.

LARENTIS, F. et al. Aprendizagem Organizacional e Relacionamentos Interorganizacionais: Um Estudo de Casos Múltiplos. BASE - Revista de Administração e Contabilidade da Unisinos, v. 11, n. 4, p. 347-366, 2014.

LARENTIS, F.; ANTONELLO, C. S.; SLONGO, L. A. Organizational Culture and Relationship Marketing: An Interorganizational Perspective. Revista Brasileira de Gestão de Negócios, v. 20, n. 1, p. 37-56, 2018.

LARENTIS, F.; ANTONELLO, C. S.; SLONGO, L. Inter-Organizational Culture: Linking Relationship Marketing with Organizational Behavior. Cham (Switzerland): Springer, 2019.

LAVE, J., WENGER, E. Situated learning: legitimate peripheral participation. Cambridge University. Press, 1991.

LIU, C. E. An investigation of relationship learning in cross-border buyer-supplier relationships: The role of trust. International Business Review, v. 21, n. 3, p. 311-327, 2012.

MERRIAN, S. B.; TISDELL, E. Qualitative research: a guide to design and implementation. 4. ed. San Francisco: Jossey-Bass, 2016.

MORGAN, R. M. Relationship Marketing and Marketing Strategy. In: SHETH, J. N.; PARVATIYAR, A. (ed.). Handbook of Relationship Marketing. Thousand Oaks: Sage, 2000. 
MORGAN, R. M.; HUNT, S. D. The commitment-trust theory of relationship marketing. Journal of Marketing, v. 58, n.3, p. 20-38, Jul. 1994.

MOZZATO, A. R.; BITENCOURT, C. C. Understanding interorganizational learning based on social spaces and learning episodes. BAR-Brazilian Administration Review, v. 11, n. 3, p. 284-301, 2014.

NEMBHARD, I. M. All teach, all learn, all improve?: The role of interorganizational learning in quality improvement collaboratives. Health Care Management Review, v. 37, n. 2, p. 154, 2012.

NICHOLSON, C. Y.; COMPEAU, L. D.; SETHI, R. The role of interpersonal liking in building trust in long-term channel relationships. Journal of the Academy of Marketing Science, v. 29, n. 1, p. 3-15, 2001.

NICOLINI, D.; GHERARDI, S.; YANOW, D. Introduction: toward a practice-based view of knowing and learning in organizations. In: NICOLINI, D.; GHERARDI, S.; YANOW, D. (ed.). Knowing in organizations: a practice-based approach. New York: M. E. Sharpe, 2003.

NOGUEIRA, R. A.; ODELIUS, C. C. Desafios da pesquisa em aprendizagem organizacional. Cadernos EBAPE. BR, v. 13, n. 1, p. 83-102, 2015.

NONAKA, I.; TOYAMA, R.; HIRATA, T. Mananing flow: teoria e casos de empresas baseadas no conhecimento. Porto Alegre: Bookman, 2011

O'CASS, A.; WEERAWARDENA, J. The effects of perceived industry competitive intensity and marketing-related capabilities: Drivers of superior brand performance. Industrial Marketing Management, v.39, p.571-581, 2010.

OLIVEIRA, G. M.; SILVA, A. B. How can inter-organizational learning and dynamic managerial capability improve cluster performance?. Revista Eletrônica de Estratégia \& Negócios, v. 13, n. 1, p. 145-168, 2020.

PALMATIER, R. W. et al. Factors influencing the effectiveness of Relationship Marketing: a meta-analyses. Journal of Marketing, v. 70, p. 136-153, Oct. 2006.

PALMATIER, R. W.; STEINHOFF, L. Relationship marketing in the digital age. New York: Routledge, 2019.

PAYNE, A.; FROW, P. Relationship marketing: looking backwards towards the future. Journal of services marketing, v. 31, n. 1, p. 11-15, 2017.

RAJALA, Anni. Examining the effects of interorganizational learning on performance: a metaanalysis. Journal of Business \& Industrial Marketing, v. 33, n. 4, p. 574-584, 2018.

SÁNCHEZ, J. A. L.; SANTOS-VIJANDE, M. L.; GUTIÉRREZ, J. A. T. The effects of manufacturer's organizational learning on distributor satisfaction and loyalty in industrial markets. Industrial Marketing Management, v. 40, p. 624-635, 2011. 
SANZO, M. J. et al. Trust as a moderator of the relationship between organization al learning and marketing capabilities: Evidencefrom Spanish SMEs. International Small Business Journal, v. 30, n. 6, p. 700-726, 2012.

SCHAKETT, T. et al. Effects of Social Bonding in Business-to-Business Relationships. Journal of Relationship Marketing, v. 10, n. 4, p. 264-280, 2011.

SCHEER, L. K.; MIAO, C. F.; PALMATIER, R. W. Dependence and interdependence in marketing relationships: Meta-analytic insights. Journal of the Academy of Marketing Science, v. 43, n. 6, p. 694-712, 2015.

SHETH, J. Revitalizing relationship marketing. Journal of Services Marketing, v. 31, n. 1, p.610, 13 fev. 2017.

SELNES, F.; SALLIS, J. Promoting Relationship Learning. Journal of Marketing, v. 67, p, 80-95, jul. 2003.

TURLEY, D.; GEIGER, S. Exploring salesperson learning in the client relationship nexus. European Journal of Marketing, v. 40, n. 5/6, p. 662-681, 2006.

WANG, Q. et al. Creativity in buyer-seller relationships: The role of governance. International Journal of Research in Marketing, v. 25, n. 2, p. 109-118, 2008.

WEICK, K. E.; WESTLEY, F. Aprendizagem organizacional: confirmando um oximoro. In: CLEGG, S. R.; HARDY, C.; NORD, W. R. Handbook de estudos organizacionais. São Paulo: Atlas, 2004. v. 3.

WINKLHOFER, H.; PRESSEY.A.; TZOKAS, N. A cultural perspective of relationship orientation: using organisational culture to support a supply relationship orientation. Journal of Marketing Management, v. 22, n. 1, p. 169-194, Feb. 2006.

YANG, C.; LAI, C. Relationship learning from organizational knowledge stores. Journal of Business Research, v. 65, p. 421-428, 2012.

YANG, S. et al. Knowledge exchange and knowledge protection in interorganizational learning: The ambidexterity perspective. Industrial Marketing Management, v. 43, n. 2, p. 346-358, fev. 2014. 